\title{
RHETORIC AND PHILOSOPHY IN PLATO'S PHAEDRUS
}

One of the main concerns of Plato's Phaedrus is rhetoric. This concern pervades the dialogue right from the opening scene, where Phaedrus someone with an obsessive and conspicuously superficial attachment to speech-making - is seen taking a walk in the country, having just come from hearing the great orator Lysias deliver a display speech $\left(\epsilon^{\prime} \pi i \delta \epsilon \iota \xi \iota s\right)$. There follows a sequence of three speeches: Phaedrus' reading of Lysias' speech, followed by Socrates' two speeches. In the latter half of the dialogue, the scene shifts from a presentation of rhetoric to an extended discussion about rhetoric. In particular, it presents an extended critique of contemporary rhetoric, and outlines what Plato takes to be the 'true $\tau \epsilon^{\prime} \chi \nu \eta$ ' (techne - 'art', 'craft', or 'science') of rhetoric.

Clearly there is much that is of interest in the Phaedrus for a student of Plato's view of rhetoric, but what I wish to examine in this article is the discussion of the 'true $\tau \epsilon^{\prime} \chi \nu \eta$ ' that appears in the second half of the dialogue. At first glance, Plato's aim in this discussion seems fairly transparent: namely, to offer a series of concrete proposals for how contemporary rhetoric should be modified and reformed so as to become a rational and beneficial $\tau \epsilon^{\prime} \chi \nu \eta$. If this is right, then the second half of the Phaedrus is essentially a kind of handbook or manual for producing the best kind of rhetoric - one that is intended to supersede the other handbooks in circulation. ${ }^{1}$ However, there are good reasons to doubt whether this is, in fact, the aim of the Phaedrus. For one thing, it is unclear - at least without a good deal of supporting evidence - that Plato intended any of his dialogues to serve such a direct 'practical' purpose. More importantly, Plato's account of the true $\tau \epsilon^{\prime} \chi \nu \eta$ seems to place rhetoric quite close to philosophy itself, and in particular to philosophical dialectic. And if that is the case, one may reasonably wonder whether Plato's supposed 'reformation' of rhetoric really amounts to a euthanization of it - that is, an exhortation for us to abandon rhetoric as traditionally conceived (as a form of practical political speech) in favour of a higher-order, philosophical form of discourse.

\footnotetext{
${ }^{1}$ Cf. Pl. Phdr. 271c.
} 
So how exactly does Plato conceive of the relation between rhetoric and philosophy in the Phaedrus? That is the key question at stake here, and the question that I wish to address in this article. I do not believe that Plato's main aim, despite appearances to the contrary, is to enter into an in-house debate with contemporary orators as to the relative merits of this or that rhetorical technique; nor do I believe that he is seriously suggesting a 'new' or 'better' kind of rhetoric that he envisages being practised in the Athenian Assembly or courtrooms. The 'true rhetoric' to which the Phaedrus refers is (I will argue) something akin to a heuristic or regulative ideal: that is, a form of discourse whose main features can be indicated or pointed to, but which can never be fully instantiated in practice. Moreover, I will argue that it is none other than philosophical dialectic that is the best approximation of that ideal - and, accordingly, that it is dialectic (and not persuasive political speech) that is the highest form of discourse. Hence, Plato is not trying to tell the orators how to do their job, but rather is urging them to abandon their job in favour of the philosophical life. This can be seen through the way in which Plato characterizes the preconditions of the 'true rhetoric', and through the fact that it is dialectic - and not any sort of set speech such as Socrates' own palinode - that comes closest to fulfilling those preconditions. In fact, given Plato's strict criteria, no human discourse could meet those preconditions completely; but that is just to say that all human discourse falls short of complete adequacy, and that the best that we can do is to become lovers of wisdom (that is, philosophers).

\section{The descriptive account of rhetoric}

Let us begin by considering what Plato says about rhetoric in the Phaedrus. His account of rhetoric in the second half of the dialogue contains both a descriptive and a normative element. I will examine each of these in turn.

First of all, the second half of the Phaedrus provides a descriptive account of rhetoric - that is to say, an account of what rhetoric is. What is noteworthy about this account is the very broad way in which 'rhetoric' is being defined, such that it is includes not only the kinds of speeches given in the Assembly or in the courtroom but also other the kinds of discourses not ordinarily thought of as 'rhetorical'. This 
broadening of scope can be seen, first of all, in the way in which Socrates begins the discussion about rhetoric (258d):

So what distinguishes good from bad writing? Do we need to ask this question of Lysias or anyone else who ever did write anything or who ever will write anything - whether a public or a private document, poetic verse or plain prose? ${ }^{2}$

Socrates repeats this programmatic remark at 259e: 'We ought to examine the topic we proposed just now: When is a speech well written

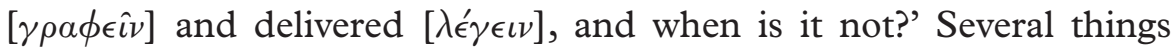
are noteworthy about these programmatic remarks. First, the inquiry in the second half of the Phaedrus will be concerned with both oral and written discourse; in other words, 'rhetoric' will include not just oral speeches but also certain types of written compositions. ${ }^{3}$ Second, the inquiry is broad in its temporal scope, as it will consider all writers and speakers, from past, present, and future. Third, the inquiry will consider a wide range of kinds of composition - not only the public or political discourse of professional orators but also private discourse, as well as certain kinds of poetry. Overall, then, Socrates frames the inquiry in a deliberately broad and non-traditional way, and in effect suggests a new working definition of what 'rhetoric' is. Rather than being limited to political or forensic set speeches, 'rhetoric' now encompasses a wide range of discourse.

The re-conceptualization of rhetoric becomes explicit at 261a, where Plato formally announces his new 'definition':

Isn't the rhetorical art, taken as a whole, a way of directing the soul by means of speech

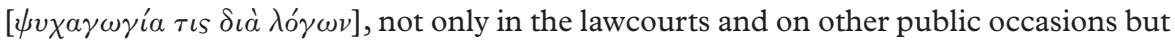
also in private? Isn't it one and the same art whether its subject is great or small, and no more to be held in esteem - if it is followed correctly - when its questions are serious than when they are trivial? ${ }^{4}$

Phaedrus' puzzled reaction to this proposal - he thinks that 'rhetoric' takes place only in the law courts and Assembly (261b3-5) - would

\footnotetext{
${ }^{2}$ Translation (slightly modified) from A. Nehamas and P. Woodruff, Plato. Phaedrus (Indianapolis, 1995). Unless otherwise noted, all translations in this article are taken from their edition.

${ }^{3}$ Cf. C. J. Rowe, Plato. Phaedrus, revised edition (Warminster, 2000), 194-5; D. A. White, Rhetoric and Reality in Plato's Phaedrus (Albany, NY, 1993), 181; and W. S. Cobb, The Symposium and the Phaedrus. Plato's Erotic Dialogues (Albany, NY, 1993), 157. The conjunction $\lambda \lambda^{\prime} \gamma \epsilon \iota v$ кai $\gamma \rho a \phi \epsilon \hat{i v}$ occurs at $259 \mathrm{e} 2,271 \mathrm{~b} 8$, and $272 \mathrm{~b} 1$.

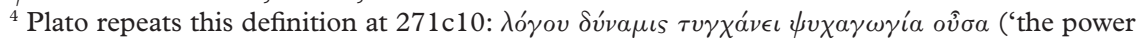
of words [or speaking] is a leading of the soul'). Also note $261 \mathrm{e} 1-2$, where Plato says that there is one $\tau \epsilon^{\prime} \chi \nu \eta$ of rhetoric that governs all speaking ( $\left.\pi \dot{\alpha} \nu \tau \alpha \tau \dot{\alpha} \lambda \epsilon \gamma o ́ \mu \epsilon \nu \alpha\right)$.
} 
probably have been shared by most Greeks, and shows that Plato's definition is novel and unconventional. ${ }^{5}$ Again we see the very broad scope of Plato's conception of rhetoric: it includes both public and private discourse, and is not restricted to a particular kind of subject matter. ${ }^{6}$ And by defining rhetoric as psychagogia, Plato widens the scope even further: any use of words to lead the soul - or, equivalently, to persuade - counts as 'rhetoric.'

Central to Plato's conception of rhetoric is the notion of persuasion. In fact, the definition of rhetoric just noted - rhetoric as a $\psi v \gamma \alpha \gamma \omega \gamma^{\prime} i^{\prime} a$ $\tau \iota s \delta \iota \dot{\alpha} \lambda{ }^{\prime} \gamma \omega \nu$ ('leading of the soul through words', 261a) - also implicitly defines rhetoric as persuasion. After all, to lead a soul is to lead it towards a particular end, belief, or proposal that one wishes to promote - in other words, to persuade that soul to accept that end, belief, or proposal as its own. Later in the dialogue, Plato explicitly makes this point: the orator's goal, he says, is to produce or engender persuasion $(\pi \epsilon \iota \theta \dot{\omega})$ in the soul $(271 \mathrm{a} 2)$. In a sense, then, rhetoric, psychagogia, and persuasion are interchangeable terms in the Phaedrus, as all ultimately point back to a soul-directed activity.

As Morrow notes, the Greeks in general held an ambivalent attitude toward persuasion. The verb $\pi \epsilon i \theta \epsilon \iota$ meant 'getting a person to do something you want him to do, by the use of almost any means short of physical compulsion'; and traditionally Peitho (Persuasion) itself was a goddess. ${ }^{8}$ Such a power was useful to possess - and admirable to behold - but also potentially dangerous. Plato himself shares this ambivalent attitude. He fully recognizes persuasion as a powerful means of influencing others' behaviour and beliefs, but one of his main concerns in the Phaedrus is to distinguish proper versus improper uses of that power. Phaedrus notes, for instance, that persuasive rhetoric is a 'very forceful power' in mass gatherings or assemblies (268a) and Socrates fully agrees. This is why Socrates describes Protagoras

${ }^{5}$ B. K. Duffy, 'The Platonic Functions of Epideictic Rhetoric', PhE Rh 16 (1983), 91.

${ }^{6}$ See E. Asmis, 'Psychagogia in Plato's Phaedrus', ICS 11 (1986), 154-5.

${ }^{7}$ R. Hackforth (Plato's Phaedrus [Cambridge, 1952], 115-16) puts the point well: rhetoric is 'any form of address, spoken or written, on any subject, in which a man seeks to commend his proposals or opinions to his audience... rhetoric is at bottom persuasion, and persuasion is generically the same whatever be the mode of its expression, oral or written, poetry or prose.' See also C. Kauffman, 'The Axiological Foundations of Plato's Theory of Rhetoric', Central States Speech fournal 33 (1982), 354. It may be a bit much to suggest, however - as J. McCumber does ('Discourse and Psyche in Plato's Phaedrus', Apeiron 16 [1982], 34) - that rhetoric 'covers speech with anyone about anything'.

${ }^{8}$ G. R. Morrow, 'Plato's Conception of Persuasion', PhR 62 (1953), 236-236 and n. 6. Morrow further notes that the passive form of $\pi \epsilon i \theta \epsilon \iota \nu$ can mean 'obey'. 
as someone who 'charms' his audiences with 'incantations', since he (Protagoras) is able to arouse any sort of emotion or response that he wishes to produce $(267 \mathrm{c}-\mathrm{d})$. Similar metaphors of 'charms', 'incantations', 'wizardry', and 'bewitchment' recur frequently in the dialogues in Plato's discussions of rhetoric. ${ }^{9}$ Elsewhere in the Phaedrus, Plato uses a medicinal analogy to describe the power of persuasion: just as the doctor produces health and strength in the body by applying the appropriate medicines and diet, so too does the orator produce 'convictions' $(\pi \epsilon \iota \theta \dot{\omega})$ and 'virtue' ( $\dot{\alpha} \rho \epsilon \tau \dot{\eta} \nu)$ in the soul

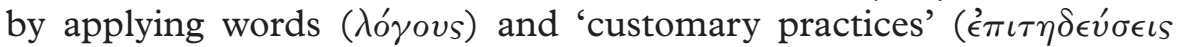
vouímovs) (270b).

Precisely because the ability to persuade is so powerful, however, it also becomes a source of great moral concern for Plato. In his view, the orators and sophists of his day were merely interested in persuading the audience, regardless of whether the recommended course of action was good (either for the city as a whole or for the individuals in the audience); moreover, he saw such orators as valuing persuasion above truth, and indeed as either being wholly ignorant of the truth themselves or else recommending that one conceal the truth if it was rhetorically advantageous to do so (260a, 267a, 272d, 273b-c). As a result (according to Plato), unscrupulous orators merely 'court the opinions of the many' - they frame speeches on the basis of what the audience thinks is right (as opposed to what really is right) - and hence often persuade the city to do evil deeds rather than good ones (260c)..$^{10}$

${ }^{9}$ See H. F. North, “'Swimming Upside Down in the Wrong Direction': Plato's Criticism of Sophistic Rhetoric on Technical and Stylistic Grounds", in $\Pi A P A \triangle O \Sigma I \Sigma$. Studies in Memory of Edwin A. Quain (New York, 1976), 23-4, for some of the references. She notes - interestingly that Socrates himself is often described in the same terms.

${ }^{10} \mathrm{M}$. Warner describes Plato's concern well: 'If our concern is primarily with persuasion, then what matters is what our audience can be led to believe rather than what is true; thus we are liable to presuppose the assumptions of our hearers in what we say, rather than accepting as premises only those assumptions which can be shown to be true' (Philosophical Finesse. Studies in the Art of Rational Persuasion [Oxford, 1989], 34). It is worth noting, incidentally, that Plato's assessment of his contemporary orators and sophists may not present a wholly accurate picture; cf. M. Gagarin, who argues that Plato's view of rhetoric is the result of a 'fundamentally conservative critical position', and that Plato misrepresents the actual methods and beliefs of the orators and sophists ('Probability and Persuasion: Plato and Early Greek Rhetoric', in I. Worthington [ed.], Persuasion. Greek Rhetoric in Action [London, 1994], 46-68). Gagarin's analysis serves, at the very least, as a useful reality check for the modern commentator: it is one thing to analyse Plato's view of rhetoric; but we must guard against uncritically assuming that such a view is also a fully accurate representation of historical fact. A failure to heed this warning has hindered a full appreciation of the historical phenomenon of oratory and sophistry. See also Everett Lee Hunt ('Plato and Aristotle on Rhetoric and Rhetoricians', in A. M. Drummond 
In addition to addressing the question of what rhetoric and persuasion are, the descriptive account of the Phaedrus is also concerned with how persuasion is brought about (and what are the best methods for bringing it about). It is in this latter area that the sophists and orators claim to have the greatest advantage, for they maintain that they have discovered and mastered the $\tau \epsilon ́ \chi \nu \eta$ - the 'art', 'craft', or 'science' - of persuasive speech. (They further claim that this $\tau \epsilon^{\prime} \chi \nu \eta$ is teachable.) Much of Plato's concern in the second half of the dialogue is to

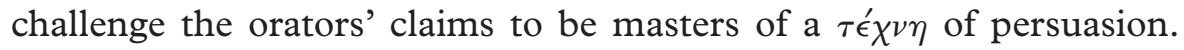
He ultimately argues that, unless one practises philosophy adequately, one can never be an effective speaker on any subject (261a). In other words, only the philosopher can come closest to practising rhetoric as a genuine $\tau \epsilon^{\prime} \chi \nu \eta$; by contrast, other orators do not practise a $\tau \epsilon^{\prime} \chi \nu \eta$ at

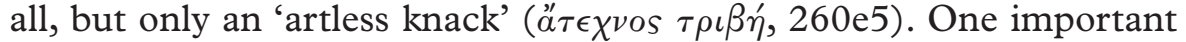
implication of this view is that the philosopher can potentially become a more persuasive speaker than even the professional orators. ${ }^{11}$

In an important respect, however, Plato is in agreement with the orators and sophists - namely, with respect to the cause of persuasion in an audience. The central claim of the orators and sophists is that effective speaking does not require a knowledge of truth but only an

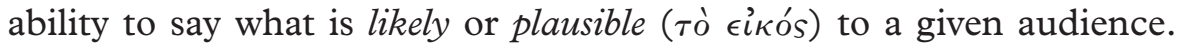
For instance - it is claimed - an orator need not know what justice really is ( $\left.\tau \dot{\alpha} \tau \hat{\omega}{ }^{\prime} \nu \tau \iota \delta^{\prime} \kappa \alpha \iota \alpha\right)$ but only what seems to be just ( $\tau \dot{\alpha}$ $\delta{ }^{\prime} \xi \alpha \nu \tau o$ ) to the audience (that is, what the audience thinks is just or can be made to believe is just) (259e-260a). But popular belief ( $\delta o ́ \xi \alpha)$ and likelihood ( $\tau$ ò $\epsilon i k o ́ s)$ are one and the same; hence it turns out that the underlying cause of persuasion is likelihood or plausibility

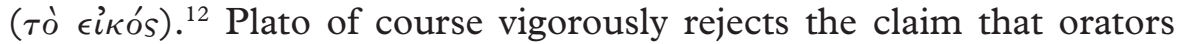
should dispense with the truth or forego knowledge of the truth; in

[ed.], Studies in Rhetoric and Public Speaking [New York, 1962], 3-5) on this point, especially the quotation from Gomperz on p. 5.

${ }^{11}$ Plato is not naïve, however; he fully recognizes that philosophical knowledge alone is not sufficient for producing persuasion. Most notably, at $269 \mathrm{~d}$ he suggests that the ability ( $\tau$ o $\delta v ́ v a \sigma \theta a \iota)$ to become an accomplished speaker rests on three characteristics: nature ( $\phi \dot{v} \sigma \iota s)$, knowledge $\left(\dot{\epsilon} \pi \iota \sigma \tau \eta^{\prime} \mu \eta\right)$, and practice $\left(\mu \epsilon \lambda \epsilon^{\prime} \tau \eta \nu\right)$. (Evidently this triad was fairly common in some

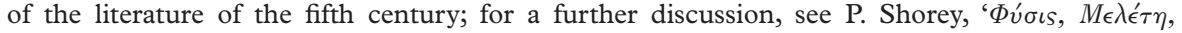
'E $\pi \sigma \tau \eta^{\prime} \mu \eta$ ', TAPhA 40 [1909], 185-201.) So knowledge itself is only part of the picture. (In this sense Plato would agree - albeit in a qualified way - with the orator's claim at $260 \mathrm{~d} 7-9$.) Nor does Plato deny that current orators are, as a matter of fact, quite persuasive. His point, rather, is that only the philosophical orator is persuasive in a scientific ( $\left.\tau \epsilon^{\prime} \chi \nu \eta\right)$ manner, and that - given the appropriate $\phi \dot{v} \sigma \iota s$ and $\mu \epsilon \lambda \epsilon^{\epsilon} \tau \eta \nu$ - such an orator will ultimately be the most persuasive.

${ }^{12}$ These claims (as put forth by the orators) are explicitly made at 272d8-e1 (persuasion $=$

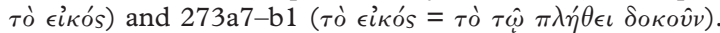


fact, the entire upshot of his discussion of 'antilogic' at $261 \mathrm{c}-262 \mathrm{~b}$ is that the very ability to persuade (and deceive) an audience by way of subtle plausibilities requires a knowledge of the truth, simply as a practical matter (since one cannot say what is 'similar' or 'likely' without a dialectical knowledge of similarities and differences) ${ }^{13}$ But that very same discussion of antilogic also shows that Plato agrees with the orators and sophists as to the underlying cause of persuasion. To wit: he agrees that it is through subtle similarities or plausibilities ( $\tau$ ò दikós) that persuasion comes about and that an audience can be made to believe a given proposal. ${ }^{14}$ In other words, Plato agrees that orators will be effective by appealing to $\tau \dot{\alpha} \epsilon i \kappa a \sigma^{\prime} \alpha$, that which is likely or plausible; and that, in turn, means that the effective orator will need to appeal to the audience's current belief set, $\tau \dot{\alpha} \delta \delta^{\prime} \xi \alpha \nu \tau \alpha$ (that which an audience currently believes; or, equivalently, that which currently seems best to the audience).$^{15}$ For a given proposal or idea will seem 'plausible' (єiкós) only if it is consonant with at least some elements of an auditor's belief set ( $\left.\delta o^{\prime} \xi \alpha \iota\right)$; in the absence of such consonance, persuasion will be difficult, if not impossible, to bring about.

\footnotetext{
${ }^{13}$ J. M. Cooper puts the point well: 'What makes some fact seem to the many a likely basis for concluding that an action was wrong is that actions so characterized actually do resemble, more or less closely, wrong actions. And, Socrates adds, the person who knows the truth about wrongness will obviously be in the best position to assess which features that might be claimed for the actual case do resemble wrongness most closely, in the right sort of way, etc., to be found by those being addressed a plausible basis for arguing that it was a case of wrong action' ('Plato, Isocrates and Cicero on the Independence of Oratory from Philosophy', Proceedings of the Boston Area Colloquium in Ancient Philosophy 1 [1985], 83).

${ }^{14}$ See especially $261 \mathrm{~d} 10-\mathrm{e} 4$ : 'Then the science of antilogic is not only concerned with lawcourts and public addresses, but, so it seems, there will be this one science - if indeed it is one - in relation to everything that is said, by which a man will be able to make everything which is capable of being made to resemble something else resemble everything which it is capable of being made to resemble, and to bring it to light when someone else makes one thing resemble another and disguises it' (translation by Rowe [n. 3]).

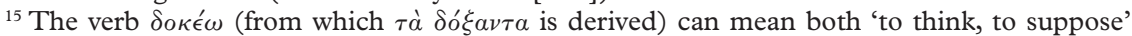
and (in an impersonal sense) 'to seem best or good to someone'. Plato often has both meanings in mind at once. Again, Cooper (n. 13) has a helpful remark: 'If he [the orator] is arguing that the act was wrong, his task is to assemble some plausible grounds that might persuade his audience that the act possessed that property. But, Socrates holds, he won't know how to do that...unless he knows which among the things that are open to him to say about the act in question are, in the minds of his hearers, closely enough connected to wrongness so that they will accept them as sufficient reasons to conclude that the act was wrong' (81).
} 


\section{The normative account of rhetoric}

Plato's descriptive account of rhetoric thus includes both a definition of what rhetoric is (namely, a kind of persuasion and 'leading of the soul through words') and a description of how it operates (namely, on the basis of certain probabilities or plausibilities). However, his main concern in the second half of the Phaedrus is to give a normative account of rhetoric, that is, to prescribe what rhetoric ought to be (when practised rightly). The orators and sophists of Plato's day professed to be masters of a $\tau \epsilon^{\prime} \chi \nu \eta$ and further professed to be able to teach that $\tau \epsilon^{\prime} \chi \nu \eta$ to anyone. Plato regarded such claims as both false and dangerous: false in the sense that current orators (in his view)

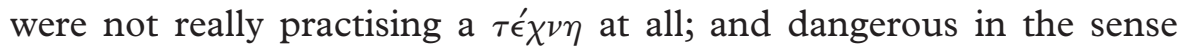
that the kind of rhetoric being practised had (in his view) unacceptable moral consequences. In the second half of the Phaedrus Plato thus lays out his conception of the 'true' or 'genuine' $\tau \epsilon^{\prime} \chi \nu \eta$ of speaking. His account is deliberately intended to undercut the orators' claims both to discursive authority and to rhetorical expertise.

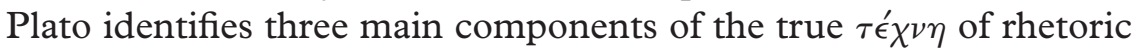
- requirements or preconditions that need to be met if one is to practise the art of speaking in a truly systematic (or philosophical) way. These requirements are as follows:

1. Knowledge of truth. The orators and sophists of Plato's day (at least on Plato's reading of them) claimed that a good speaker does not need to know the truth about the subject matter of his speech but only needs to know what is tikós (likely or plausible) regarding it - in other words, that which will be persuasive to an audience $(259 \mathrm{e}-260 \mathrm{a}$, $272 \mathrm{~d}-273 \mathrm{c}$ ). Plato vigorously rejects this claim in the Phaedrus, and does so on two grounds. First, for a speaker to be ignorant of the truth is morally problematic, since such a speaker - being ignorant of what 'good' and 'bad' really are - might very well persuade his audience to

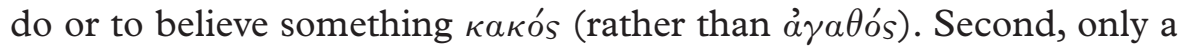
speaker who has precise knowledge of the subject matter of his speech will best be able to persuade (or deceive) an audience, and in turn to avoid being deceived $(261 \mathrm{c}-262 \mathrm{c}, 273 \mathrm{~d}-\mathrm{e}) .{ }^{16}$ Hence Plato insists that

\footnotetext{
${ }^{16}$ Briefly, Plato's argument for this second claim runs thus: persuasion (or deception) occurs on account of plausibilities ( $\tau \dot{o} \epsilon i \kappa o ́ s)$, i.e. on account of certain similarities or likenesses; hence, in order to create a speech that is єikós, one must know the truth of the subject matter, so as to be able to know which things are in fact 'similar' to that truth. In this way, Plato can both agree with the sophists that persuasion comes about as a result of $\tau \dot{o}$ єikós, and simultaneously disagree with their claim that the successful orator need not have any knowledge of the truth.
} 
a true orator must have knowledge of the truth of the subject matter of his speech. For example, one who wanted to speak in a 'scientific' or 'artful' ( $\left.\tau \epsilon^{\prime} \chi \nu \eta\right)$ way in a forensic case would need to know what justice really is - the Form of Justice - beyond simply knowing what would seem to be just to a given audience (since the latter depends on the former).

2. Knowledge of soul. In addition to having knowledge of the subject matter, the true orator needs to have knowledge of the object of his speeches - that is, the human soul. In other words, in order to be able to apply speeches to the soul, one must first know about the soul itself. Plato identifies at least five things that the true orator must know about human psychology: whether the soul is simple or complex; the natural powers by which the soul acts on and is acted upon by other things; the kinds of soul that exist; the kinds of speeches that exist; and which sorts of speeches are appropriate for which sorts of soul, which sorts of soul are persuaded by which sorts of speeches, and the reasons for this causal efficacy (270b-272b). These five things are part of what it means to know the nature ( $\phi \dot{v} \sigma \iota s)$ of the soul, though the list is probably not meant to be an exhaustive description of the science of psychology. In addition to this 'theoretical' dimension of psychology, the true orator must also have a 'practical' or 'contextual' knowledge: the ability to recognize the distinctive soul-types within his audience in real life, to offer the appropriate speech(es) for those soultypes, and to know when to speak or to remain silent $(271 \mathrm{e}-272 \mathrm{a})$. Part of Plato's point, then, is that good rhetoric should be ad hominem: that is, speech that is offered and adapted for the particular needs and conditions of a particular soul.

3. Structural organization ('organic unity'). Finally, there is a formal requirement of true rhetoric. A good speech should not be haphazardly arranged but should proceed in accordance with 'logographic

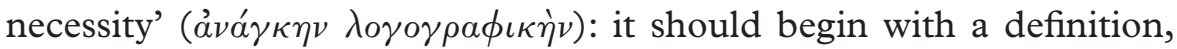
and have everything that follows arranged in relation to the definition; its order of presentation should be logical and orderly; and, like a living creature, it should have a 'head', 'body', and 'legs', each of which should be fitting to the others and to the whole $(263 \mathrm{~d}-264 \mathrm{e}$, $265 d, 269 a-c)$.

Such are the main conditions that Plato lays out as the foundation of true rhetoric, and in his view such conditions are not met by any of the contemporary orators or sophists. This then raises the question: 
what would the 'true rhetoric' look like, if it were brought to fruition? The remainder of this article will be devoted to answering this question.

\section{The palinode as true rhetoric?}

Many commentators on the Phaedrus have suggested that the palinode itself is an example of the true rhetoric that Plato discusses in the second half of the dialogue. ${ }^{17}$ This view is supported on the grounds that (it is claimed) the palinode meets each of the three conditions of the true $\tau \epsilon^{\prime} \chi \nu \eta$ of rhetoric: first, the speech is written by a philosopher who knows the truth about the subject matter, namely, the Forms and the soul (the truth requirement); second, it is fitted for the particular needs of its audience's souls, namely Phaedrus himself (the psychology requirement); and third, it begins with a classification (definition) of madness, and is clearly organized as a proof (the structural requirement). ${ }^{18}$

The view that the palinode is an example of the true rhetoric is certainly attractive in many respects; among other things, it provides a neat solution to the 'problem of unity' of the dialogue, and it also underscores the importance of the showing-telling dynamic in the dialogue. ${ }^{19}$ However, a closer inspection reveals that such a view cannot be correct, since the palinode conspicuously fails to meet each of the three requirements of the true $\tau \epsilon^{\prime} \chi \nu \eta$. I will consider each of these three requirements in turn. First, the truth requirement. Plato insists that the true orator must have knowledge of the subject matter of his speech, and indeed that the orator must have precise and

\footnotetext{
${ }^{17}$ For proponents of this view, see W. H. Thompson, The Phaedrus of Plato (London, 1868), xiii-xviii; W. K. C. Guthrie, Plato. The Man and His Dialogues. Earlier Period, vol. 4 of A History of Greek Philosophy (Cambridge, 1975), 415-16; idem, 'Rhetoric and Philosophy: The Unity of the Phaedrus', Paideia (1976), 121-2; J. E. Smith, 'Plato's Myths as "Likely Accounts", Worthy of Belief', Apeiron 19 (1985), 37-8; Rowe (n. 3), 10; C. J. Rowe, 'Public and Private Speaking in Plato's Later Dialogues', in Conrado Eggers Lan (ed.), Platon. Los Dialogos Tardios, Actas del Symposium Platonicum (Sankt Augustin, 1994), 132-3; idem, 'The Argument and Structure of Plato's Phaedrus', PCPhS 212 (1986), 108-10; J. V. Curran, 'The Rhetorical Technique of Plato's Phaedrus', Ph\&Rh 19 (1986), 66-70; Asmis (n. 6), 153-72; and Nehamas and Woodruff (n. 2), xxviii-xxix.

${ }^{18}$ In fact, those who claim that the palinode is an example of true rhetoric rarely spell out an argument in the precise terms in which I have done so; rather, the rhetorical status of the speech is usually 'presumed' to follow from the fact that it is the most 'natural' (or perhaps the 'only') way of relating the two halves of the dialogue to each other. The simplicity of the interpretation, in other words, is supposed to guarantee its truth.

${ }^{19}$ For more on this issue, see my 'Plato's Phaedrus and the Problem of Unity', OSAPh 32 (2007), 91-137.
} 
complete knowledge.$^{20}$ Yet the contents of the palinode - most notably, its psychology, eschatology, and metaphysics (Theory of Forms) - are such that they cannot be known with completeness or precision (at least not in this life); and indeed Plato himself explicitly brings this fact to our attention. Consider, for example, the palinode's account of the nature of the soul (its psychology). Plato famously employs the image of the winged chariot to describe the tripartite nature of the soul. His reason for using such an image is significant:

To describe what the soul actually is would require a very long account, altogether a task for a god in every way; but to say what it is like is humanly possible and takes less time. So let us do the second in our speech. (246a; italics mine)

In other words, the use of a mythical image to discuss the soul is not merely a result of the particular dialogical context or the particular nature of Socrates' interlocutor (though it is no doubt related to those things also). Rather - and more fundamentally - it is also a reflection of the fact that no human can possibly give a complete and adequate account of the nature of the soul (as it is) - such would be a task that could be completed only by a god. The problem, moreover, concerns the limitations of human knowledge, and not just human discourse or language ${ }^{21}$ Consequently, no human - including the author of the palinode - could possibly have the complete knowledge of soul (the subject matter) required by the true rhetoric.

This same problem applies to the broader eschatological narrative of the soul that Plato offers in the palinode. Quite clearly, no mortal - Plato included - could possibly have the kinds of eschatological knowledge that the palinode purports to provide, since no one except the gods can be certain of the soul's history before birth or fate after

\footnotetext{
${ }^{20}$ Plato's language is quite clear and strong: the true orator must make a systematic division ( $\delta \delta \hat{\omega} \delta \iota \eta \rho \hat{\eta} \sigma \theta \alpha \iota)$ of the subject and grasp the appropriate distinctions (263b); he must be able to divide $\tau \dot{\alpha}$ oै $\nu \tau \alpha$ (all things) according to their kind and to subsume each thing ( $\left.\epsilon^{\prime \prime} \alpha \sigma \tau o \nu\right)$ under one form (273e); and he must be able to define everything ( $\pi \hat{\alpha} \nu)$ and again to divide it appropriately (277b). Partial knowledge is not sufficient for the true $\tau \epsilon^{\prime} \chi \nu \eta$.

${ }^{21}$ One might object here: what if there is a Form of Soul? In that case, couldn't the philosopher in fact have knowledge of it? To this I reply, first, that there is no hint whatsoever in the Phaedrus that there is a Form of Soul. Moreover, notorious problems and inconsistencies arise in Plato's metaphysics if we do acknowledge the existence of such a Form. (For instance, what would it mean for an individual soul - which is ungenerated and indestructible, and which fully is a soul - to 'participate' in a Form or 'fall short' of a Form? It is also hard to understand how something that is 'akin to' and 'of the same kind as' the Forms [Phd. 79d] could simultaneously have a Form.) Finally, even if there were such a Form, that would not guarantee the kind of knowledge that Plato requires of the true orator. More on this last point in a moment.
} 
death. ${ }^{22}$ So far, then, it is clear that palinode fails the truth requirement with respect to two of the key topics of the speech (namely, psychology and eschatology, neither of which permit precise knowledge). But what about the metaphysics of the palinode, the famous Theory of Forms? Does not Plato believe that it is precisely the philosopher who is capable of attaining complete knowledge of the Forms? And if so, would not a speech (or myth) written by a philosopher about the Forms qualify as an example of 'true rhetoric'?

In fact, a closer examination of the Phaedrus reveals a negative answer to this last question. Though the issue is complex - and would require a full-scale examination of Plato's epistemology (which is well beyond the scope of this paper) - we may note two key points that emerge in the course of the Phaedrus: first, complete knowledge of the Forms can only be attained through direct acquaintance, via a kind of

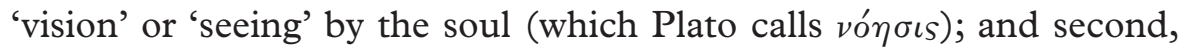
such a direct 'vision' can be attained only in the soul's discarnate state and not in our incarnate state; consequently, complete knowledge of the Forms is unattainable in our present (incarnate) form. I will address each of these points in turn. ${ }^{23}$

According to the palinode, cognition of the Forms occurs through the rational part of the soul (the charioteer). More specifically, the cognition - as shown in the discarnate soul's encounter with the Forms during its heavenly ascent - consists in a direct and unmediated insight. Or, in the language of the myth, the soul 'sees' or has a 'vision' of the Forms. Indeed, ocular metaphors for the experience of knowledge acquisition abound throughout the palinode, with variants of i $\delta \epsilon \hat{\imath} \nu$, ó $\rho \alpha \omega$ (both 'see', 'behold'), and $\theta \epsilon a ́ \omega$ ('gaze upon') occurring over a dozen times within just a few Stephanus pages. ${ }^{24}$ Of course this is not a case of literal 'seeing', since the Forms themselves do not exist in space and time and are not the kind of thing that is perceptible to any of the senses; rather, it is vov - 'mind' or the 'pilot of the soul' (247c7-8) - that 'sees' the Forms. What the ocular metaphors suggest, however, is that the soul's knowledge of the Forms is what we would nowadays call (following Bertrand Russell) a kind of direct knowledge

\footnotetext{
${ }^{22}$ Nor can one recollect such matters, since recollection is aimed solely at the Forms. See $249 \mathrm{~b}-\mathrm{c}$.

${ }^{23}$ For a more extensive treatment of some of the issues involved here, see my 'Plato's Epistemology in the Phaedrus', Skepsis 18 (2007), 279-303.

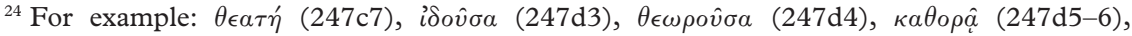

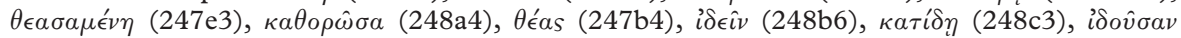

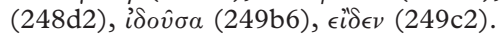


by acquaintance, rather than knowledge by description. ${ }^{25}$ Whereas the latter type of knowledge is based on some discursive or propositional account - as articulated (or at least potentially so) in language - the former type of knowledge is based on some direct insight or intuition. Indeed, we may note that, in the narrative of the divine banquet, the only activity that the soul undertakes - other than that of motion and horse-yoking - is that of 'seeing' (or attempting to see) the Forms; discussion, dialogue, and dialectic are entirely absent. ${ }^{26}$ Knowledge of the Forms, then, is acquired through a direct noetic cognition and not through a discursive or propositional account.

Now to the second point. If genuine knowledge consists in a direct noetic vision, the key question is this: Does Plato believe that such knowledge is attainable? If so, when? The answer of the Phaedrus, I believe, is clear: it is only in our discarnate state - when soul is separated from the body - that we can achieve vó $\eta \iota s$. Several passages support this view. For example, at $247 \mathrm{~d}-\mathrm{e}$ Plato contrasts the pure, stable $\dot{\epsilon} \pi \iota \sigma \tau \eta^{\prime} \mu \eta$ that the gods (and certain discarnate souls) achieve - a knowledge that takes the Forms ( $o^{\prime \prime} \epsilon \sigma \tau \iota \nu$ oै $v$ ) as its direct object,

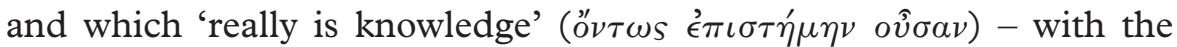
partial, unstable $\epsilon \pi \iota \sigma \tau \eta \dot{\mu} \mu$ that is available to fallen souls and that is

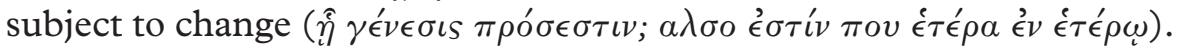
Moreover, in describing the procession of souls in the heavens, Plato notes that, when a given soul finally ascends to the point where it

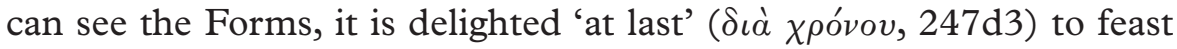
upon true being. This phrase makes sense only if we assume that the direct vision of the Forms was previously denied to the soul - in other words, that, in the soul's last series of incarnations, it conspicuously lacked the direct, noetic vision. ${ }^{27}$ But this means that such knowledge does not occur in this life, and that, when a discarnate soul - a soul that has just been freed from incarnation - attains such knowledge, it

\footnotetext{
${ }^{25}$ For the distinction between knowledge by acquaintance and knowledge by description, see Chapter V of Russell's The Problems of Philosophy (Oxford, 1912). For a good discussion (and defence) of the view that Plato's epistemology employs a model of knowledge by acquaintance, see Anne Mary Farrell, 'Plato's Use of Eleusinian Mystery Motifs' (unpublished PhD thesis, University of Texas at Austin, 1999). I am very much indebted to Farrell's insightful work.

${ }^{26}$ As R. Burger notes, this is why the gods have no need for speech (Plato's Phaedrus. A Defense of a Philosophic Art of Writing [University, AL, 1980], 56).

${ }^{27}$ Of course, the soul would have had to have seen the Forms at some point in its prior history, else it would never have been born in human form (and hence would never have been a candidate for being freed from incarnation). But such a noetic vision could only have occurred in a prior discarnate period, and not in a prior incarnate period.
} 
is doing so for the first time (and hence can see true being 'at last'). ${ }^{28}$ Finally, the palinode consistently emphasizes the notion of purity, and the fact that incarnation inevitably involves a certain lack of purity. So it is, for example, that incarnate souls are locked in a body 'like an oyster in its shell' (250c), forced to rely on 'dull organs' to perceive the ultimate reality (249b). In sum, then, Plato quite clearly maintains in the Phaedrus that no (incarnate) human can have complete knowledge of the Forms.

Such a view may strike some readers as surprising; after all, does not Plato seem to suggest - both in the Phaedrus and elsewhere - that the incarnate philosopher can attain knowledge by way of recollection? To be sure, Plato does consistently argue that recollection of the Forms is the goal of the (incarnate) philosopher's inquiries. The question, however, is whether such recollection achieves the complete cognition of the Forms that vónoıs does - and I maintain that it does not. As a cognitive experience, recollection - being indirect - is fundamentally different in kind from the discarnate soul's noetic knowledge. Moreover, the former is epistemically inferior to the latter. There are several reasons for this (although Plato does not explicitly spell these out in the Phaedrus). First, Plato seems to think that there is a fundamental difference in terms of vividness, as recollected knowledge is less vivid than a discarnate soul's first-hand knowledge. And, given the eschatology of the palinode - with its vast stretches of time, and its emphasis on the disruptive cognitive effects of incarnation - this difference of vividness should be understood to be quite severe: it is not simply a case of (say) trying to remember a phone number but of trying to remember a metaphysical vision that one's soul experienced hundreds or even thousands of years prior to one's birth. ${ }^{29}$ Moreover, we must keep in mind what recollection is supposed to be recollection of: namely, a noetic 'vision'. So, for example, we would say that the experience of remembering the face of a childhood friend is different from - and inferior to - the experience of seeing that face at first hand. Plato seems to hold that the same is true of the difference

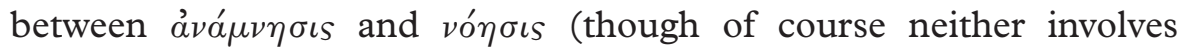
literal 'seeing'). Whereas in the former the mind operates merely on itself, in the latter the mind has direct 'contact' with its object.

\footnotetext{
${ }^{28}$ See previous note.

${ }^{29}$ Moreover - since Plato holds that only Forms are recollectable - an incarnate soul cannot recollect the experience of pure knowing; at most it can recollect the result. However, merely knowing the result is not enough.
} 
Plato even offers us a few hints as to why incarnate, recollective knowledge inevitably falls short of pure vó $\eta$ $\iota s$. If what I argued above is correct, true knowledge is attained via direct acquaintance and not descriptive or discursive accounts. There is an implied reason for this: namely, that the Forms are not the kind of thing that can be adequately described via language; in other words, that the Forms are in some sense ineffable. Notice, for example, Plato's pithy remark at 247c: 'the region above the heavens [the Forms] has never yet been celebrated as it deserves by any earthly poet, nor will it ever be'. Here Plato is making a significantly broad claim. No previous poet has ever adequately sung about the Forms, nor will any future poet ever $(\pi \circ \tau \epsilon)$ do so. This implies that the subject matter inherently defies discursive expression - in other words, that any attempt to describe the Forms in words will inevitably be inadequate. Indeed, Plato's own attempt in the palinode to describe (discursively) the Forms falls flat; his cryptic attempts to characterize the Forms - for instance, as 'being that

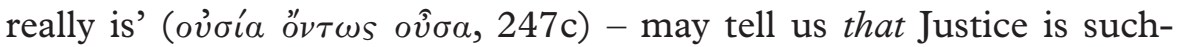
and-such ('true being') but fails to illuminate us as to what Justice actually is. Yet, if the Forms are ineffable, that helps to explain why he regards incarnate cognition - including philosophical recollection - as incomplete. To wit: recollection is a result of philosophical dialectic and dialogue, and dialectic is itself a linguistic activity. In other words, it may very well be that recollection is in some sense 'contaminated' by the activity that triggers it. ${ }^{30}$

Let us return now to my original claim. I have argued that, according to Plato, no potential orator can know the complete truth about psychology, eschatology, or the Forms, and hence - since knowledge of the complete truth of one's subject matter constitutes the first precondition of the true rhetoric - no potential orator can offer a fully 'artful' or 'scientific' ( $\left.\tau \epsilon^{\prime} \chi \nu \eta\right)$ speech on such subjects. It

\footnotetext{
${ }^{30}$ It has been well pointed out to me (by an anonymous reviewer) that even if the process that leads to recollection (namely, dialectic) is imperfect or incomplete, it does not necessarily follow that the recollective experience itself is imperfect or incomplete. This is quite correct; however, in my view there are still good grounds for regarding even the recollective experience itself as incomplete. For one thing (as noted above), recollection itself still suffers from the problems of diminished vividness and directness. Moreover, Plato seems to regard thought itself as inherently discursive or linguistic (see Tht. 189e-190a and Soph. 263e, where Plato claims that thinking consists in the soul having a 'silent conversation' with itself.) From this it would follow that recollection - as a mode of incarnate human thought - is inextricably bound up with language, and thereby falls short of fully capturing the Forms. The issues involved here are clearly beyond the scope of this paper, so I will not attempt to say anything beyond this; but, at the very least, I find some justification for casting doubt on the adequacy of recollective knowledge.
} 
now follows from this that the palinode also fails to meet the other two requirements of the true rhetoric. Consider the psychology requirement: Plato insists that the true orator must know the exact nature of the soul - its simplicity or complexity, its different forms, and its causal interactions with objects. ${ }^{31}$ But as we have just seen, such precise knowledge is unattainable (at least by a mortal); although the philosopher may be able to learn something about the soul, only a god can provide the long and complete account. Or again, consider the structural requirement of true rhetoric: Plato insists that a good speech must begin from a clear definition of the subject matter. Yet in the absence of clear, stable knowledge, one will never be in a position to know - with some degree of finality - whether one's definition is correct. $^{32}$ This is clearly a problem in the palinode, given that the definition in question (of love and madness) is intricately bound up with the soul - that subject on which we conspicuously lack complete knowledge.

\section{The unattainability of the true rhetoric}

So, by Plato's own standards, the palinode cannot qualify as an example of the true rhetoric, since it clearly fails to meet any of the three preconditions of the $\tau \epsilon^{\prime} \chi \nu \eta \cdot{ }^{33}$ And in fact this exemplifies a more

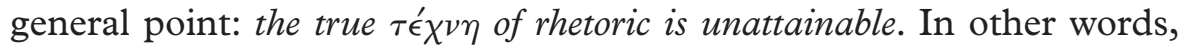

\footnotetext{
${ }^{31}$ Again, Plato's language is clear and strong: the true orator must be able to demonstrate

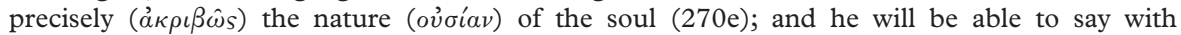
complete precision $(\pi \dot{\alpha} \sigma \eta \dot{\alpha} \kappa \rho \iota \beta \epsilon i \alpha)$ what the nature of the soul is (271a). Again, partial knowledge is not sufficient. In addition to these passages, at 270c Plato says that it is impossible to know the nature of anything without knowing the nature of 'the whole' ( $\tau \circ \hat{v}$ ó $\lambda_{o v}$ ); I would argue - following Guthrie (Plato, n. 17), 431 n. 4, and White (n. 3), 237-8 - that this means that it is impossible to know the nature of the soul without knowing the nature of the cosmos in general. If such a reading is correct, we again see that Plato is requiring total knowledge of the true orator.

${ }^{32}$ It is true that at $265 \mathrm{~d}$ Socrates says that, regardless of whether his definition of love and madness was correct, he was still able to produce a 'clear' and 'consistent' speech. Yet we should not press this too far: for it is certainly the presupposition behind the entire method of the elenchus that all false definitions will eventually lead to some sort of inconsistency. Indeed, Socrates seems to make this very point at $237 \mathrm{c}$, where he notes that a failure to reach an adequate definition inevitably leads us to be in conflict with ourselves and our dialogical partners.

${ }^{33}$ It is worth pointing out, however, that even though the palinode is not itself an example of the true rhetoric, nonetheless it is, in one important sense, about the true rhetoric. For the palinode depicts, in vivid detail, the plight of two philosophical lovers who - among other things - engage in philosophical conversation in the course of their struggle to overcome their own worst elements. Such is the nobler type of persuasive psychagogia toward which Plato wishes to point us. I will say more about such dialectical discourse below.
} 
Plato has set the bar for the $\tau \epsilon^{\prime} \chi \nu \eta$ so high that no orator (philosophical or otherwise) could possibly meet it. ${ }^{34}$ For one thing - as I noted in the previous paragraph - the kind of precise psychological knowledge that Plato requires is unattainable (at least in this life), and the kinds of precise substantive knowledge (of the subject matter of one's speech) that he requires are also unattainable. ${ }^{35}$ In short (as one commentator put it), Plato seems to require 'nothing less than the comprehensive wisdom for which the philosopher searches unendingly'. ${ }^{36}$ Moreover, the ad hominem requirement - the requirement that an orator know the soul-types of his audience and fit his speeches to those soul-types accordingly - would be impossible to meet in any context in which an orator would typically find himself. For, in addressing a mass audience such as the Assembly or a pool of jurymen, how could an orator possibly fit his speech to the hundreds (or thousands) of soultypes who would be represented within that audience ${ }^{37}$ This suggests that the true $\tau \epsilon^{\prime} \chi \nu \eta$ is not likely to be achieved in any mass address, or indeed in any context that relies upon a lengthy set piece (such as the palinode).

Plato himself signals the unattainability of his $\tau \epsilon^{\prime} \chi \nu \eta$ at several points in the Phaedrus. At 271c7-8 Socrates says that he will describe what

${ }^{34}$ Cf. R. Waterfield, Plato. Phaedrus (Oxford, 2002), xxxv-xxxvi; see also Hunt (n. 10), who notes that 'the ideal rhetoric sketched in the Phaedrus is as far from the possibilities of mankind as his Republic was from Athens' (42). I would only add to this that the problem is not simply a pragmatic or logistical one but also an epistemological one. (In addition, of course, Plato does not say in the Republic that the ideal state is actually impossible - whereas he does imply that the ideal rhetoric is impossible.)

${ }^{35}$ To be able to speak about just actions, for instance, an orator would need to know what justice is, i.e. would need to know the Form of Justice; but complete knowledge of such a Form (as I have suggested) is unattainable in this life. In addition, there is the fact (already noted) that the exactness and completeness that Plato requires are unattainable.

${ }^{36}$ J. C. Koritansky, 'Socratic Rhetoric and Socratic Wisdom in Plato's Phaedrus', Interpretation 15 (1987), 47. Or, as O. L. Brownstein put it, the requirement is for 'absolute knowledge of everything' ('Plato's Phaedrus: Dialectic as the Genuine Art of Speaking', Q7S 51 [1965], 397).

${ }^{37}$ Cf. Guthrie ('Rhetoric and Philosophy', n. 17), 122; and Waterfield (n. 34), xxxvi. One might object here that Plato does not actually require knowledge of the individual souls within the audience but only a knowledge of their soul-types. To this I reply, first, that even a knowledge of soul-types would be impossible to attain in any mass address, not only because of the logistical difficulties but also because the Phaedrus has set no limit on the number of possible soul-types there might be. But, more importantly, Plato's descriptions make it clear that he is in fact requiring knowledge of individual souls, and not just soul-types. At 271e-272a, Plato suggests that there is a contextual knowledge that the true orator must possess (relative to each given situation): the content and style of one's speech need to vary in response to both the population of the audience and the particular proposal that one is trying to recommend. And in fact there are certain occasions when one should not speak at all. Clearly, the ability to do this depends on knowing who one's audience is, and not just what it is (i.e. what soul-types the audience members possess). In addition, I would suggest that the drama of the Phaedrus shows us an 'orator' (Socrates) who knows both who and what his audience (Phaedrus) is. 
one must do in order to become 'as artful as possible' ( $\tau \epsilon \chi \nu \iota \kappa \hat{\omega} s$ '́ $\chi \epsilon \iota \nu$

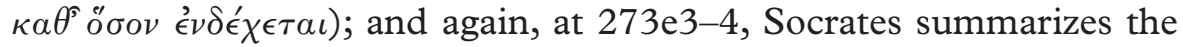
requirements of the $\tau \epsilon^{\prime} \chi \nu \eta$, and says that by meeting those requirements one will become an artful speaker 'to the extent that any human can'

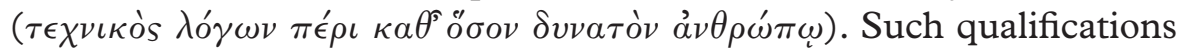
- which echo a recurring contrast in the Phaedrus between human and divine capabilities - suggest that human achievements in the pursuit of the $\tau \epsilon^{\prime} \chi \nu \eta$ have an unavoidable limit. In other words, one can at most approximate the true $\tau \epsilon^{\prime} \chi \nu \eta$ but cannot attain it fully; we can achieve a certain extent, but no more. ${ }^{38}$ Indeed the overall passage at $273 d-274 b$ reinforces this view: Socrates describes the requirements of the $\tau \epsilon^{\prime} \chi \nu \eta$ as a 'long road', and says that it is to be travelled for the sake of saying and doing what is pleasing to the gods. When Phaedrus expresses scepticism as to the attainability of such a goal ('if only it could be done!', 274a6-7), Socrates' reply is telling: 'for a man who

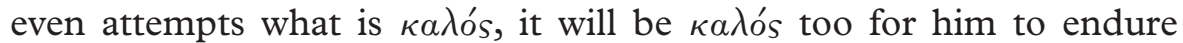
whatever comes about'. In other words, the process or activity of striving for the $\tau \epsilon^{\prime} \chi \nu \eta$ is itself worthwhile, even if it is not or can never be completed. ${ }^{39}$

Yet even if Plato's ideal of rhetoric is unattainable, one might still wonder: can we not regard the palinode as the best possible approximation of that ideal? More broadly, might not Platonic myth be the best kind of 'rhetorical' speech of which humans are capable? These questions, however, receive a negative answer when we consider the broader thrust of the Phaedrus. To see that this is the case, we must examine the relation between dialectic and rhetoric in the Phaedrus.

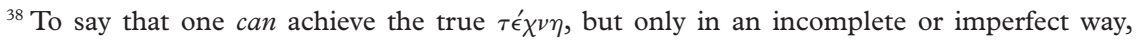
misses the point; for Plato, an imperfect instantiation is not the genuine article.

${ }^{39}$ This is Plato's response to those who would complain that the demands of the ideal rhetoric are unreasonable, or that the ideal itself is far-fetched (T. Conley voices this complaint in 'Phaedrus 259e ff', Rhetoric Society Quarterly 11 [1981], 14). As Burger (n. 26) put it, 'the desirability of the true art of speaking cannot be judged by its attainability' (89) (see also Kauffman [n. 7], 359). This passage also provides a reply to those who see an alleged 'contradiction' between Plato's requirement of precise knowledge of the soul at 270bff, and his denial of the attainability of such knowledge at 246a (for this view, see C. L. Griswold, Jr, Selfknowledge in Plato's Phaedrus, revised edition [University Park, PA, 1996], 192; Cobb [n. 3], 151; and White [n. 3], 242).
} 


\section{Dialectic as a prerequisite for the true rhetoric}

In the Republic, Plato valorizes dialectic as the culmination of the process of philosophical education. ${ }^{40}$ In the Phaedrus, he continues this strong valorization, although his conception of the methods of dialectic seems to show some new developments. He explicates this method - referred to as 'collection and division' - in a terse passage at $265 \mathrm{~d}-266 \mathrm{c}$. In general terms, dialectic is the abstract discourse with which the philosopher conducts inquiry and seeks substantive knowledge. Specifically, dialectic is concerned with (or directed toward) the Forms. ${ }^{41}$ There are two aspects to the method of dialectic. On the one hand, there is 'collection', a process of cognitive synthesis (265d):

Seeing together things that are scattered about everywhere and collecting them into

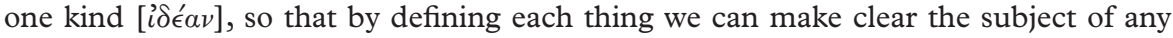
instruction we wish to give.

On the other hand, there is 'division', a process of cognitive classification (265e):

To be able to cut up each kind [ $\left.\epsilon \imath^{\prime} \delta \eta\right]$ according to its species along its natural joints, and to try not to splinter any part, as a bad butcher might do.

${ }^{40}$ See Pl. Resp. Book 7.

${ }^{41}$ Some commentators deny this claim, and suggest instead that the 'new' dialectic of the Phaedrus - in contrast to the earlier dialectic of the Republic - merely involves some kind of conceptual analysis and has little or no relation to the Forms (see, e.g., Griswold [n. 39], 190ff). I find such a claim highly implausible. Here are some considerations: (1) even if one wishes to deny that $\kappa \alpha \tau^{\text {s } \epsilon \prime \delta \eta ~(' a c c o r d i n g ~ t o ~ i t s ~ f o r m ') ~ i n ~} 265 \mathrm{e} 1$ refers specifically to the Forms - a view that I find questionable in itself - it is hard to read such phrases as $\tau \hat{\omega} \nu$ o $\nu \tau \omega \nu$ ('the things that

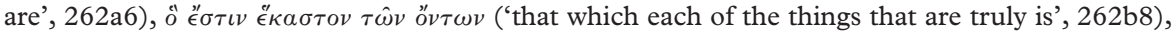
and $\tau \dot{\alpha}$ ' $\nu \tau \tau \alpha$ ('the things that are', 273e2) as referring to something other than the Forms; (2) Plato's description of recollection (at 249b-c) and his description of collection (at 265d) are very similar, suggesting that the two processes are closely related (if not identical); (3) Plato emphasizes that one's pre-natal vision of the Forms is what enables us to be human and to use language $(249 \mathrm{~b}-\mathrm{c}, 249 \mathrm{e})$, but he makes the same claim for dialectic (that which enables us to think and to speak, 266b); and (4) if we seriously claim that collection and division have no relation to the Forms, then we must also be willing to admit that the Phaedrus is a patently disunified and self-contradictory text, for Plato would be announcing a philosophical method in the second half that had no relation to the metaphysics of the first half. For these reasons, then, I take it that there is a close relation between the methodological dialectic of the second half of the dialogue and the metaphysical theory of Forms in the palinode. Specifically, I take it that dialectic is directed toward the Forms; and conversely, that one's pre-natal vision of the Forms is the very precondition of dialectic. (For more along these lines, see G. Nicholson, Plato's Phaedrus. The Philosophy of Love [West Lafayette, IN, 1999], 66, 73-4; also Burger [n. 26], 81.) 
Plato situates dialectic at the centre of the philosophical life: it is that practice in which the philosopher alone engages, and in which he engages par excellence..$^{42}$ Dialectic also seems to have a much broader significance, as Socrates declares it to be that which enables him 'to think and to speak' (266b). Overall, then, dialectic is essential both to the practice of philosophy and to the very process of thought.

There has been much discussion in the secondary literature as to the nature of dialectic, its technical aspects, and its changing form from Plato's middle dialogues to the later dialogues; it is beyond the scope of this paper to enter into those discussions. My concern, rather, is with a broader issue: the overall status or value of dialectic, particularly in relation to myths such as the palinode. As a first approach to this issue, let us consider the relation of dialectic to the ideal $\tau \epsilon^{\prime} \chi \nu \eta$ of rhetoric that Plato outlines in the second half of the Phaedrus. Earlier we saw that Plato lays out three key conditions of the ideal $\tau \epsilon^{\prime} \chi \nu \eta$ : a truth requirement, a psychology requirement, and a structure requirement. A closer look at the second half of the dialogue, however, reveals that it is dialectic that is in fact the necessary basis for each of these conditions to be met. In other words, the possibility of bringing the true $\tau \epsilon^{\prime} \chi \nu \eta$ to fruition - or, more precisely, of bringing it to fruition to the extent that is humanly possible - is grounded on the practice of dialectic.

That dialectic is the necessary basis of each of the three requirements of the true $\tau \epsilon^{\prime} \chi \nu \eta$ can be seen by considering the way in which Plato characterizes those requirements, and in particular by considering the technical language that he uses:

1. Regarding the truth requirement, Plato insists that an orator have knowledge of the subject matter of his speech; and this is because persuasion - as well as deception - comes about as a result of certain similarities and likenesses. Consequently, the true orator must know the truth about his subject matter, so as to be able to know those respects in which it can be made similar and dissimilar (and, hence, persuasive or unpersuasive). But notice how Plato puts this point: the

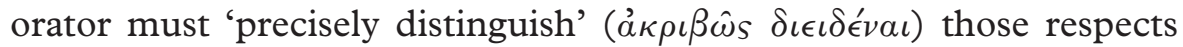
in which things are similar and dissimilar to one another (262a5-7; cf. $\delta \iota \alpha \gamma \iota \gamma \nu \omega ́ \sigma \kappa \epsilon \iota \nu$, 'distinguish', in 262a11); he must know 'what each

${ }^{42}$ Notice, for instance, that Plato several times declares dialectic to be the necessary basis of the true $\tau \epsilon^{\prime} \chi \nu \eta$ of rhetoric (see, e.g., $273 \mathrm{~d}-\mathrm{e}$ ); in the same way, however, he also declares philosophy to be the necessary basis of the $\tau \epsilon^{\prime} \chi \nu \eta$ (see 261a). So the practice of dialectic is in some sense constitutive of the life of philosophy. 


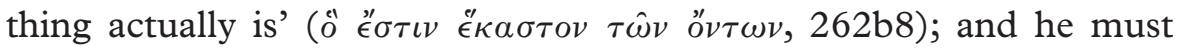
make a 'systematic division' ( $\delta \delta \hat{\omega} \quad \delta \iota \eta \rho \hat{\eta} \sigma \theta \alpha \iota)$ between disputable and non-disputable terms, and 'grasp the particular character of

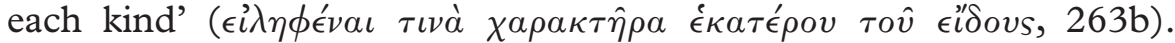
This language is an exact parallel to the language that Plato uses to describe dialectic, particularly the process of division in which one 'cuts up each kind [ $\left.\epsilon \imath^{\prime} \delta \eta\right]$ according to its species along its natural

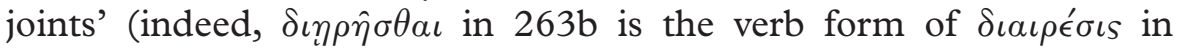
$266 \mathrm{~b}$, the latter of which Plato uses to describe the 'cutting' side of dialectic). Such a parallel makes sense: what the orator needs is a precise classification, which is exactly what dialectic seeks to provide; and what the orator needs is the truth regarding his subject matter, which is exactly what dialectic - through reflection on the Forms, the sole guarantor of truth - seeks to provide. ${ }^{43}$ So it turns out that the truth requirement of the $\tau \epsilon$ ' $\chi \nu \eta$ of rhetoric can only be met - or, more precisely, best approximated - by way of dialectic.

2. Again, we find a similar situation in regard to the psychology requirement of the true $\tau \epsilon^{\prime} \chi \nu \eta$. The true orator must 'distinguish' or 'define' the nature of the soul $\left(\delta \iota \epsilon \lambda \epsilon^{\prime} \sigma \theta a \iota, 270 b 4\right.$, the same verb as $\delta \iota \eta \rho \hat{\eta} \sigma \theta \alpha \iota$, 'divide', above); he must determine whether the soul is simple or complex and, if the latter, must 'count' ( $\alpha \rho \theta \mu \eta \sigma \alpha{ }^{\prime} \mu \epsilon \nu o \nu$, 270d6) its various forms; he must be able to make a 'precise demonstration' ( $\delta \epsilon i \xi \xi \iota \dot{\alpha} \kappa \rho \iota \beta \hat{\omega} s)$ of the nature of soul (270e3; cf. $\pi \alpha \dot{\sigma} \sigma \eta$ $\alpha \kappa \rho \iota \beta \epsilon i \alpha$ ['with complete precision'] in 271a5, and $\alpha \kappa \rho \iota \beta \hat{\omega} s$ in $262 \mathrm{a}$

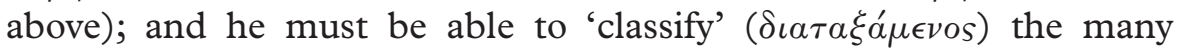
kinds $\left(\gamma^{\prime}{ }^{\prime} \nu \eta\right)$ of souls and of speeches that exist. Again we find the parallel between the description of psychology and the description of dialectic. In fact, Plato makes this connection explicit at 273e: while summarizing, he says that the true orator must be able 'to enumerate the sorts of characters to be found in any audience, to divide everything according to its kinds, and to grasp each single thing firmly by means of one form'. As in the case of the truth requirement, here too it is clear that Plato conceives of dialectic as the method whereby one is to seek knowledge of the soul, so as to be able to speak in a truly ad hominem way.

3. Finally, dialectic has a role to play in providing a speech with a sound structure or organization. Plato suggests that every good speech needs to begin with a 'definition' ( $\dot{\omega} \rho \sigma \alpha ́ \mu \eta \nu, 263 \mathrm{~d} 2)$ - that is,

${ }^{43}$ Whether dialectic succeeds in this task is another matter. More on this point later. 
a statement of the subject matter, explicating it as 'some one single thing' ( $\epsilon^{\prime \prime} \nu \iota \tau \hat{\omega} \nu$ oै $\left.v \tau \omega \nu, 263 \mathrm{~d} 8\right)$ - such that the remainder of the speech can be organized with respect to that definition; the idea is that such organization-by-definition will allow a speech to be maximally clear and self-consistent (265d). But definition is precisely what dialectic provides, vis-à-vis its 'collection' mode: 'Seeing together things that are scattered about everywhere and collecting them into one kind, so that by defining each thing we can make clear the subject of any instruction we wish to give.'

We now see that philosophical dialectic is the necessary basis or precondition of the true $\tau \epsilon^{\prime} \chi \nu \eta$ of rhetoric. The true $\tau \epsilon^{\prime} \chi \nu \eta$ can only be brought to fruition if its three conditions are met; and the best way of fulfilling - or rather, approximating - those three conditions is by using dialectic. In this sense, Plato sees dialectic as being logically prior to rhetoric. ${ }^{44}$

\section{Dialectic as the best approximation of the true rhetoric}

Yet we can take this last point even further. For not only is dialectic the necessary precondition for the true $\tau \epsilon^{\prime} \chi \nu \eta$ of rhetoric; in fact dialectic is the form of discourse that comes closest to actually being that $\tau \epsilon^{\prime} \chi \nu \eta$. In other words, dialectic is the best approximation of the ideal rhetoric that Plato outlines in the second half of the Phaedrus. But how is such a seemingly counterintuitive conclusion possible? Does Plato not see rhetoric and philosophy as diametrically opposed?

We may first note that the view of dialectic as the near-fulfilment of true rhetoric follows almost as an inevitable consequence of Plato's description of the three conditions of the $\tau \epsilon^{\prime} \chi \nu \eta$; that is, each of the three conditions points toward dialectic as its logical end point. First,

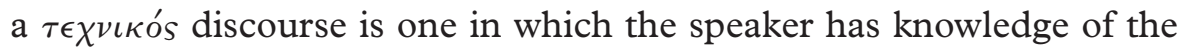
subject matter. But only the Forms are, properly speaking, the objects of knowledge; consequently, the only possible speech in which an orator could potentially know the subject matter is a speech about the Forms. ${ }^{45}$ And dialectic just is a 'speech' or discourse about the Forms a linguistically framed method of inquiry that is directed at the highest

\footnotetext{
${ }^{44}$ Kauffman (n. 7), 361.

${ }^{45}$ Again, for more on this aspect of Plato's epistemology, see my 'Plato's Epistemology' (n. 23).
} 
objects of cognition. ${ }^{46}$ Second, true rhetoric must be ad hominem: that is, an orator must adapt a specific kind of speech for a specific kind of soul. ${ }^{47}$ Yet the maximal fulfilment of this condition will occur only in one-on-one dialogue, in which an 'orator' (a philosophical teacher) is confronted with only one 'listener' (a philosophical student) - and hence only one soul-type - and can continually adapt and change his discourse from moment to moment. By contrast, any speech before a mass audience will be incapable of being adapted to the plurality of souls represented in the audience. Although Plato's own speeches - his myths such as the palinode - avoid this problem by being presented in a private setting, they still suffer from the limitation of being set speeches of fixed length - that is, they are protracted discourses that are incapable of being interactive and of responding to the momentto-moment demands of a particular soul. ${ }^{48}$ The best kind of rhetoric, then, will need to be both private (one-on-one) and interactive. Once again, dialectic meets these criteria. Finally, true rhetoric must proceed on the basis of a definition, and must proceed in a structured, consistent, and logical manner. We can easily see, however, that dialectical discourse can meet these criteria far better than any other kind of set speech. Part of the point of dialectic, after all, is to provide definitions (by way of collection; see 265d); and its entire method requires the participants to proceed in a careful and logical manner, and to move to a new step only when agreement has already been reached about the previous steps. (Perhaps the only kind of set speech that would possess - or rather, mimic - these properties is a written transcript of a dialectical exchange; but such a speech would then fall short of the ad hominem requirement.)

Textual evidence from the second half of the dialogue further confirms the view of dialectic as the true $\tau \epsilon^{\prime} \chi \nu \eta$ : without engaging in collection and division, Plato says, one will never become an artful

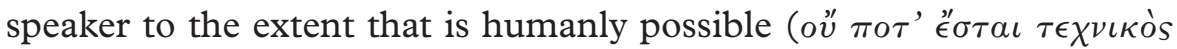

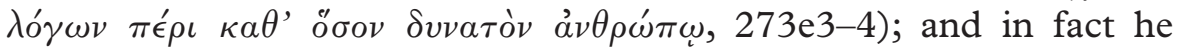
suggests that, without a knowledge of dialectic, one will be unable even to define what rhetoric is (269b6-7). More broadly, Plato uses

\footnotetext{
${ }^{46}$ Although the palinode deals partly with the Forms, it does not do so exclusively (in contrast to dialectic); moreover, it does not meet the other two conditions of the $\tau \epsilon^{\prime} \chi \nu \eta$ as well as dialectic does.

${ }^{47}$ And this, in turn, relies on the specific kind of knowledge of the soul discussed earlier.

${ }^{48}$ Recall that, even for one soul-type, a plurality of different speech-types will be needed, depending on the kind of proposal that is being advanced.
} 
the term $\tau \epsilon^{\prime} \chi \nu \eta$ several times to characterize dialectic itself (265d1, $266 \mathrm{c} 3,266 \mathrm{~d} 2$ ).

It is worth emphasizing - in light of what I argued earlier - that,

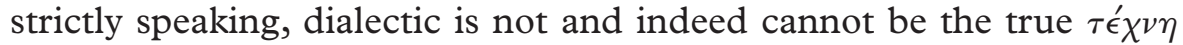
itself, since that $\tau \epsilon^{\prime} \chi \nu \eta$ is unattainable by any incarnate human. Rather, dialectic is the best approximation of the true $\tau \epsilon^{\prime} \chi \nu \eta$ of rhetoric. Indeed, even though dialectic comes closest to fulfilling the three conditions discussed above, it nonetheless does so imperfectly and incompletely. Specifically, the incarnate dialectician (as I have already suggested) cannot attain complete knowledge of any of the Forms or of the soul - or at the very least, cannot attain such knowledge within the process of dialectic itself. Hence the dialectician could not completely meet either the truth requirement or the psychology requirement - though he would do so better than all other kinds of orators.

\section{Conclusion}

It turns out, then, that dialectic - and not Platonic myth - is the form of discourse that comes closest to the 'true rhetoric' that Plato outlines in the Phaedrus. In short, the best form of rhetoric in Plato's view is none other than philosophical discourse. Several implications of this view are worth noting.

The first concerns the question of Platonic myth. Although the issue of myth - what 'myth' is for Plato, and why he uses it in his dialogues - is far too complex to consider here, one salient point has now emerged: Plato quite clearly subordinates $\mu \hat{v} \theta 0 s$ to dialectical $\lambda o ́ \gamma o s$, at least from the point of view of epistemic adequacy. For one thing,

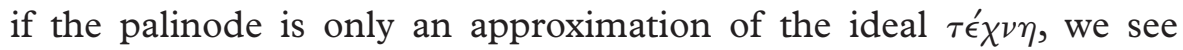
immediately that it is not itself an ideal; in other words, Platonic myth is not itself an ideal or 'best' mode of discourse that the philosopher ought to emulate. Moreover, as a mode of discourse that approximates the ideal $\tau \epsilon^{\prime} \chi \nu \eta$ to a lesser degree than does dialectic, Platonic myth is clearly subordinate to the latter mode of discourse. This suggests that myth is not the philosopher's end point, but only a stepping stone.

Second, we now see that, in a very broad sense, dialectic itself is a form of 'rhetoric'. Such a claim is not as counterintuitive as it might seem; it simply points to the fact that dialectic conforms to the broad definition of rhetoric that Plato states at 261a. That is, dialectic itself is a form of psychagogia, a leading of the soul through words; specifically, 
it involves the use of argumentative and analytical words that lead the soul of the dialectician toward a greater understanding of concepts, terms, and Forms. ${ }^{49}$ The definition at $261 \mathrm{a}$ also made a distinction between public and private speech-making. We can now see that the 'speech-making' of dialectic falls into the latter category: it is 'private' both in the sense of being used among a small number of conversation partners (in contrast to a mass audience) and in the sense of being limited to a select group of practitioners (the philosophers, in contrast to the masses). In other words, while the sophists offer long speeches in public, the philosopher offers short speeches (arguments) in private. ${ }^{50}$ Overall, then, we can now better appreciate a claim I made earlier namely, that Plato deliberately re-defines 'rhetoric' in the Phaedrus so as to include many kinds of discourse; dialectic is one such type of discourse. Once this is understood, there is no contradiction involved in declaring dialectic to be a form of rhetoric; 'rhetoric' here is simply being defined in a non-traditional way.

This now leads me to a final point. If dialectic represents the best approximation of the ideal $\tau \epsilon^{\prime} \chi \nu \eta$ of rhetoric, then we find a curious situation: in the process of supposedly 'reforming' rhetoric - indicating what rhetoric ought to be - Plato has all but done away with it. Or, as Conley puts it, 'Plato...here set conditions for the rehabilitation of rhetoric which guarantee that it would redeem itself only by an act of self-immolation. ${ }^{51}$ This is because the true orator does not practise speech-making in any traditional sense; the true orator is a philosopher. ${ }^{52}$ In other words, the ideal rhetoric merges with philosophy:

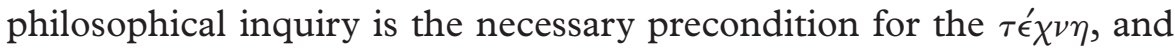
philosophical discourse is the nearest approximation of that $\tau \epsilon^{\prime} \chi \nu \eta$. So the kind of rhetoric practised by Plato's contemporaries drops out of the picture - or else it 'self-immolates' (to use Conley's phrase) in the act of becoming philosophically respectable. The kind of discourse

\footnotetext{
${ }^{49}$ More precisely, dialectic helps to effect philosophical recollection, which in turn brings one closer to the Forms.

${ }^{50}$ Cf. Rowe ('Public and Private Speaking', n. 17), 126. Rowe takes his cue from Pl. Soph. $268 \mathrm{~b}$.

${ }^{51}$ Conley (n. 39), 12.

${ }^{52}$ As M. Heath notes, the individual who becomes a true orator (i.e. a philosopher) will experience a shift in values as well: 'If conventional rhetoric does not become philosophical it is not a techne and cannot achieve its ends systematically; but if it does become philosophical it no longer wishes to achieve those ends. Either it dissolves itself, or it remains unfulfilled' ('The Unity of Plato's Phaedrus', OSAPh 7 [1989], 158). On the merging of rhetoric with philosophy, see also A. Lebeck, 'The Central Myth of Plato's Phaedrus', GRBS 13 (1972), 283; P. Friedländer, Plato, iii, trans. by H. Meyerhoff, second edition (Princeton, NJ, 1969), 233, 235, 237, 240; Koritansky (n. 36), 30-1; and Waterfield (n. 34), xxxv-xxxvii.
} 
that remains - philosophical dialectic - only qualifies as 'rhetoric' in the broad sense of psychagogia noted above. This is in fact a common manoeuvre in Plato's dialogues, and is a classic example of what we might call his 'assimilation strategy' - his consistent tendency to begin with commonly understood concepts and terms but to transform their meaning so as to arrive at an opposite point. More broadly, it is his tendency to assimilate all ordinary practices and activities into philosophy..$^{53}$ In this sense, the Phaedrus is not a 'manual of instruction in rhetoric' - such as a guide to win over the Assembly - but rather is 'a plea to abandon it for philosophy'. ${ }^{54}$ The Plato of the Phaedrus thus remains as hostile toward sophistic rhetoric as he ever was; and the only kind of respectable discourse is that which is 'rhetoric' in name only. ${ }^{55}$

\section{DANIEL WERNER}

wernerd@newpaltz.edu

\footnotetext{
${ }^{53}$ As Guthrie insightfully puts the point, 'The fact is that, as many of the dialogues make plain, what Plato calls the "true" representative of every human art, science or practice turns into the philosopher and bears little resemblance to his counterpart in everyday life, be he called statesman, scientist, lover, poet, or rhetorician' ('Rhetoric and Philosophy' [n. 17], 120). On Plato's practice of 'assimilation', see also R. G. Edmonds III, Myths of the Underworld Fourney. Plato, Aristophanes, and the 'Orphic' Gold Tablets (Cambridge, 2004), 167-9; and J. M. Redfield, who notes that 'For Socrates (as Plato represents him) all valid activities are one with dialectical philosophy and therefore can be included within it' (Nature and Culture in the Iliad. The Tragedy of Hector [Chicago, 1975], 44).

${ }^{54}$ Guthrie ('Rhetoric and Philosophy', n. 17), 123.

${ }^{55}$ There is a looming debate here as to whether Plato has 'changed' his view of rhetoric from the Gorgias to the Phaedrus: i.e. whether he has moved beyond the harsh condemnation of rhetoric in the Gorgias, and now expresses a more 'tolerant' view of rhetoric in the Phaedrus. My own view is that there is no such change: for one thing, the Gorgias itself admits the possibility of a good form of rhetoric (e.g. 503a-b), and hence is not 'merely' critical; and, as I have argued in this article, the supposed 'reformation' of rhetoric in the Phaedrus ultimately leads - as it does in the Gorgias - to philosophy. So I take Plato to hold a consistent view throughout the two dialogues: he is critical of most kinds of rhetoric but also suggests the possibility of a 'reformed' or 'true' rhetoric (which in the Phaedrus is equivalent to dialectic). But I do not wish to enter into the debate beyond this statement of the matter. For representatives of the 'pro-change' view, see Hackforth (n. 7), 11; W. Hamilton, Plato. Phaedrus and the Seventh and Eighth Letters (Harmondsworth, 1973), 9; C. J. Rowe, 'The Unity of the Phaedrus: A Reply to Heath', OSAPh 7 (1989), 179-81; Rowe ('Public and Private Speaking', n. 17), 127-9; Nicholson (n. 41), 35, 45, 48-53; Morrow (n. 8), 236; Warner (n. 10), 32-3; North (n. 9), 12-14; and Koritansky (n. 36), 30-1. For representatives of the 'anti-change' view, see Guthrie ('Rhetoric and Philosophy', n. 17), passim; Conley (n. 39), passim; R. W. Quimby, 'The Growth of Plato's Perception of Rhetoric', Ph\&Rh 7 (1974), 71-9; Hunt (n. 10), 42; E. Black, 'Plato's View of Rhetoric', QfS 44 (1958), 361-74; and Waterfield (n. 34), xxxv-xxxvii.
} 